\title{
Elucidating the Efficacy of Pancreatectomy for Renal Cell Metastases Remains Problematic
}

\author{
Natasha Leigh, MD, and William G. Hawkins, MD \\ Department of Surgery, Barnes-Jewish Hospital/Washington University Medical Center and Siteman Cancer Center, St \\ Louis, MO
}

To date, various studies have demonstrated the potentially curative role of metastasectomy in select primary malignancies, such as sarcomas with lung metastases ${ }^{1}$ and colorectal cancers with liver or pulmonary metastases. ${ }^{2}$ However, it is clear that "biology is King, selection is Queen, technical maneuvers are the Prince and Princess".3 Malleo et al. ${ }^{4}$ have demonstrated that clear-cell renal cell carcinoma (RCC) is yet another great example of the significance of biology and patient selection. Its more slowgrowing nature correlates with longer overall survival (OS), even in the presence of tumor recurrence or metastatic disease. ${ }^{5}$ Isolated pancreatic metastases (PM) tend to occur in a metachronous fashion years after nephrectomy and have a more indolent behavior than other sites of metastatic disease with improved survival. ${ }^{6}$

In the early era of systemic therapies for metastatic RCC, cytokine therapy was associated with significantly shorter survival when used alone than when combined with surgical metastasectomy. ${ }^{7}$ This was true in both cytoreductive nephrectomy and metastasectomy; it was the reduction in tumor burden that appeared most important. As such, metastasectomy fell into favor. However, the majority of the studies are retrospective, small cohorts with shorter-term follow-up, and conducted in the era before current, more efficacious, novel biologic agents.

(C) Society of Surgical Oncology 2021

First Received: 4 January 2021

Accepted: 15 January 2021;

Published Online: 3 March 2021

W. G. Hawkins, MD

e-mail: hawkinsw@wustl.edu
In this study, Malleo et al. reported on the long-term survival of 69 patients with isolated PM-RCC who were treated with surgical resection. ${ }^{4}$ The majority were metachronous $(87 \%)$ and single focus $(85.5 \%)$. The median interval to metastasectomy was 109 months and the postoperative morbidity and mortality rates were $34.8 \%$ and $2.9 \%$, respectively. The 10 -year cumulative incidence of RCC recurrence was $62.7 \%$, with more extensive pancreatic resection (adjusted hazard ratio [HR] 3.05, 95\% confidence interval $[\mathrm{CI}] 1.72-5.40 ; p=0.001)$ and synchronous metastases (adjusted HR 1.27, 95\% CI 0.98-2.84; $p=0.057)$ associated with a higher incidence of new recurrent disease. The recurrence-free interval after metastasectomy was the only factor that had a significant effect on disease-specific death; neither the number nor the site of new recurrence was influential. The 10-year RCCspecific death rate was $25.5 \%$. The authors concluded that long-term disease control can be achieved by resection of isolated PM-RCC in carefully selected patients.

As described above and corroborated by other authors, ${ }^{8,9}$ metastasectomy is associated with long diseasespecific survival in selected PM-RCC. Although most patients in this study developed postoperative recurrence, they were managed non-operatively and had a long survival, despite the presence of recurrent local or distant metastases. ${ }^{4}$ The recurrence-free period was the only significant predictor of survival, even with cytoreduction, and metachronous metastases seemed to derive some survival benefit from metastasectomy, while synchronous tumors did not. ${ }^{4,9}$

Considering that pancreatic surgery comes with considerable perioperative morbidity and that biology clearly drives overall outcome, one needs to ask if patients with PM-RCC truly benefit from operative intervention. It remains challenging to parse this out from the current study 
or other existing studies, as they are all innately biased by patient selection. The Memorial Sloan Kettering Cancer Center (MSKCC) risk criteria ${ }^{10}$ have been widely used to risk stratify metastatic RCC patients for therapeutic responses. Subgroup analyses from previous retrospective studies have shown that select patients who are poor risk do not benefit from a primary operative approach, while favorable or intermediate risk may derive some benefit. ${ }^{6,11}$

In this modern era, targeted biologic therapies, predominantly tyrosine kinase inhibitors (TKIs), have become first-line therapy for metastatic RCC. ${ }^{12}$ They have demonstrated a $20-30 \%$ reduction in tumor burden, with improved OS and progression-free survival (PFS) compared with cytokine therapy, ${ }^{13}$ questioning the role of surgical therapy. PM-RCC also appears to be more responsive to sunitinib than other sites of metastases. ${ }^{14}$

The only prospective trial of TKIs and surgery (CARMENA; NCT00930033) demonstrated that cytoreductive nephrectomy followed by sunitinib does not improve OS compared with sunitinib alone. ${ }^{15}$ However, about $40 \%$ of patients in each arm were poor-risk candidates, and therefore the role of cytoreductive surgery in intermediateand favorable-risk patients was not determined. To date, there are no randomized controlled trials evaluating metastasectomy compared with sunitinib. A recent retrospective review found the median PFS was equivalent in TKIs (41 months) and favorable-risk patients (41 months) who underwent metastasectomy in PM-RCC; ${ }^{5}$ however, PFS was significantly worse in intermediate- and poor-risk patients undergoing operative management compared with TKIs. The MSKCC risk group was the only significant predictor of survival; neither surgery nor concomitant metastases were predictive. Recent data also suggest that nivolumab plus ipilimumab has more favorable outcomes than sunitinib irrespective of the MSKCC risk group. ${ }^{16}$

Malleo et al. ${ }^{4}$ make an important contribution to the literature, in reporting the longest-term outcomes for this rare disease entity. In doing so, they expose the current controversy around the optimal management of PM-RCC. Considering the potential morbidity of surgery, more promising data from the use of biologics, and the indolent nature of the disease with long-term survival despite local or distant recurrence, the optimal management of PM-RCC will remain difficult to know for quite some time to come. Their data ${ }^{4}$ can be interpreted as supportive of metastasectomy given the long-term survival in select patients. These same data can also be interpreted as unsupportive of metastasectomy if we consider that biology, not surgery, is clearly the driver of long-term survival.

Current opinion remains mixed and we can draw no definitive conclusions. It may be that targeted therapy combined with metastasectomy is the best approach or that novel TKIs alone should replace operative intervention.
Clearly, patient selection remains key and this should continue to improve with our ever-increasing use of genetic sequencing and improved understanding of biologic drivers of cancer. Ultimately, the goal is to prolong survival and optimize long-term outcomes. As a result, we could conclude that we need trials to evaluate the role of surgery compared with TKIs in favorable-risk patients. Unfortunately, designing such a trial is a mathematical and financial challenge given the rarity of PM-RCC and its indolent nature. It is important to note that the use of biologics and surgery are not mutually exclusive, and many patients may benefit from several treatment options in the course of their disease. We are optimistic that increased understanding of biology will help select the optimal targeted therapies and, similarly, help select patients most likely to benefit from metastasectomy. Multidisciplinary team-directed combinations of appropriate therapies are very likely to further prolong survival for patients with PM-RCC.

DISCLOSURES Natasha Leigh and William G. Hawkins declare there are no conflicts of interest in relation to this manuscript.

\section{REFERENCES}

1. Chudgar NP, Brennan MF, Munhoz RR, et al. Pulmonary metastasectomy with therapeutic intent for soft-tissue sarcoma. J ThoracCardiovascSurg. 2017;154(1):319-330.e1. https://doi.or g/10.1016/j.jtcvs.2017.02.061.

2. Lee WS, Yun HR, Yun SH, et al. Treatment outcomes of hepatic and pulmonary metastases from colorectal carcinoma. J GastroenterolHepatol. 2008;23(8 Pt 2):e367-72. https://doi.org/10. 1111/j.1440-1746.2007.05178.x.

3. Cady B. Basic principles in surgical oncology. Arch Surg. 1997;132(4):338-46. https://doi.org/10.1001/archsurg.1997. 01430280012001 .

4. Malleo G, Salvia R, Maggino L, et al. Long-term outcomes after surgical resection of pancreatic metastases from renal clear-cell carcinoma. Ann Surg Oncol. (In press)

5. Santoni M, Conti A, Partelli S, et al. Surgical resection does not improve survival in patients with renal metastases to the pancreas in the era of tyrosine kinase inhibitors. Ann SurgOncol. 2015;22(6):2094-100. https://doi.org/10.1245/s10434-014-42567.

6. Kim SH, Park WS, Park B, Pak S, Chung J. A Retrospective Analysis of the impact of metastasectomy on prognostic survival according to metastatic organs in patients with metastatic renal cell carcinoma. Front Oncol. 2019;9:413. https://doi.org/10.338 9/fonc.2019.00413.

7. Patard JJ, Pignot G, Escudier B, et al. ICUD-EAU International Consultation on Kidney Cancer 2010: treatment of metastatic disease. EurUrol. 2011;60(4):684-90. https://doi.org/10.1016/j.e ururo.2011.06.017.

8. Anderson B, Williams GA, Sanford DE, et al. A 22-year experience with pancreatic resection for metastatic renal cell carcinoma. HPB (Oxford). 2020;22(2):312-7. https://doi.org/10. 1016/j.hpb.2019.05.019.

9. Shin TJ, Song C, Jeong CW, et al. Metastatic renal cell carcinoma to the pancreas: clinical features and treatment outcome. 
J SurgOncol. 2021;23(1):204-13. https://doi.org/10.1002/jso. 26251 .

10. Heng DY, Xie W, Regan MM, et al. Prognostic factors for overall survival in patients with metastatic renal cell carcinoma treated with vascular endothelial growth factor-targeted agents: results from a large, multicenter study. J ClinOncol. 2009;27(34):5794-9. https://doi.org/10.1200/JCO.2008.21.4809.

11. Heng DY, Wells JC, Rini BI, et al. Cytoreductive nephrectomy in patients with synchronous metastases from renal cell carcinoma: results from the International Metastatic Renal Cell Carcinoma Database Consortium. EurUrol. 2014;66(4):704-10. https://doi. org/10.1016/j.eururo.2014.05.034.

12. Moran M, Nickens D, Adcock K, et al. Sunitinib for Metastatic renal cell carcinoma: a systematic review and meta-analysis of real-world and clinical trials data. Target Oncol. 2019;14(4):405-16. https://doi.org/10.1007/s11523-019-00653-5.

13. Psutka SP, Master VA. Role of metastasis-directed treatment in kidney cancer. Cancer. 2018;124(18):3641-55. https://doi.org/10. 1002/cncr.31341.

14. Jiang W, Shi H, Zhang L, et al. Responses to targeted therapy among Organs Affected by Metastasis in Patients with Renal Cell
Carcinoma are Organ-Specific. Urol J. 2020. https://doi.org/10. 22037/uj.v16i7.6129.

15. Massari F, Di Nunno V, Santoni M. Re: Arnaud Méjean, Alain Ravaud, Simon Thezenas, et al. Sunitinib Alone or After Nephrectomy in Metastatic Renal-cell Carcinoma. N Engl J Med 2018;379:417-27: CARMENA Trial: Is This the End of Cytoreductive Nephrectomy in Patients with Clear-cell Renal Cell Carcinoma? Eur Urol Oncol. 2019;2(3):340-341. https://doi.org/ 10.1016/j.euo.2018.08.002

16. Motzer RJ, Escudier B, McDermott DF, et al. Survival outcomes and independent response assessment with nivolumab plus ipilimumab versus sunitinib in patients with advanced renal cell carcinoma: 42-month follow-up of a randomized phase 3 clinical trial. J Immunother Cancer. Jul ;8(2):e000891. https://doi.org/10. 1136/jitc-2020-000891.

Publisher's Note Springer Nature remains neutral with regard to jurisdictional claims in published maps and institutional affiliations. 